\title{
A novel SPTB gene mutation in neonatal hereditary spherocytosis: a case report and literature review
}

\author{
Yang Liu \\ Tianjin Children's Hospital \\ Li Song \\ Tianjin Children's Hospital \\ Jianbo Shu \\ Tianjin Children's Hospital

\section{Yulian Fang} \\ Tianjin Children's Hospital
}

\section{Chao Sun}

Tianjin Children's Hospital

$\mathrm{Na}$ Li

Tianjin Children's Hospital

Geli Liu ( $D$ liugeli2001@126.com )

Tianjin Medical University General Hospital

\section{Research article}

Keywords: Neonate; hereditary spherocytosis; spectrin beta gene; novel mutation

Posted Date: August 28th, 2019

DOI: https://doi.org/10.21203/rs.2.10866/v1

License: (1) This work is licensed under a Creative Commons Attribution 4.0 International License. Read Full License 


\section{Abstract}

Background: To enhance our understanding on the diagnosis and treatment of neonatal hereditary spherocytosis (HS). Methods: We summarized the clinical data and gene test results of a neonatal HS caused by a new mutation of SPTB gene. Meanwhile, a comprehensive literature review was performed. Gene sequencing and analysis was carried out for the crucial splicing signals on the exons and introns of the 302 known pathogenic genes (e.g. ANK1, SPTA1, EPB42, SLC4A1 and SPTB) associated with the genetic deficiency of erythrocyte. Results: A 26-day-old girl presented jaundice, anemia, an increased count in peripheral blood reticulocyte and spherocyte, as well as positive findings in the acidified glycerol hemolysis test. Gene sequencing revealed a new mutation of c.3737delA P. (Lys1246fs) in the exon 16 of SPTB (14q23 | NM_000347.5) gene in the patient and her father. The mutation was a frame-shifting mutation, which may result in truncation of beta-haemoglobin in erythrocyte membrane and loss of its normal function, leading to the occurrence of diseases. Conclusion: For the neonates with jaundice and anemia, family history, erythrocyte index and peripheral blood smear findings contributed to the diagnosis of HS. Gene sequencing is helpful for the diagnosis. We identified a novel mutation of SPTB gene, which may be pathogenic through modulating the activity of $\beta$-spectrin in the erythrocyte membrane.

\section{Background}

Hereditary spherocytosis (HS), known as Minkowski-Chauffard disease), a heterogenous disease, is a type of non-immune hemolytic anemia featured by spherocytes in the peripheral blood smear. The clinical manifestations of HS included anemia, jaundice and splenomegaly. Most of the neonates with HS present jaundice at the early stage, which then progress into severe anemia. For the HS neonates aged $<1 \mathrm{yr}$, the clinical manifestations were usually severe with the majority showing initial jaundice and subsequent severe anemia. In contrast, in the affected neonates of $>1 \mathrm{yr}$, the conditions showed gradual attenuation. According to the previous description, early stage diagnosis and treatment contributed to the reduction of adverse events. In North Europe and North America, the prevalence of HS in the neonates was 1/5,000 and 1/2,000, respectively [1-5]. In China mainland, between Jan. 1978 and Dec. 2013, the prevalence of HS in the male neonates $(<1 \mathrm{yr}$ ) was $0.18 / 1$ million, while the prevalence was $0.19 / 1$ million among the female counterparts [6]. To date, only $3 \%$ of the HS cases were diagnosed in hospitals on a country level or even from communities accounting for about $70 \%$ of the medical resources. In this study, we reported a neonate with HS, and summarized the clinical manifestations, laboratory test findings and gene sequencing data. Meanwhile, a complete literature research was performed. Our study contributed to the understanding and diagnosis of the HS in the neonates.

\section{Materials And Methods}

Subject

A 26-day female neonate was admitted to our hospital due to jaundice. The neonate was born via spontaneous delivery at a gestational age of 41 weeks. After birth, the neonate was fed with breast 
feeding, and the passage of meconium was normal. Jaundice was noticed about post-natal $24 \mathrm{hrs}$, and then phototherapy lasting for 2 days was given in a local hospital. Then the condition showed slight attenuation. No obvious remission or deterioration was noticed when admitting to our hospital. No soy sauce color urine, kaolin stools or torsion spasm was observed. Her father showed a history of anemia, and received cholecystectomy due to gallstone. Her mother showed a normal health status.

On physical examination, the body temperature was $36.5^{\circ} \mathrm{C}$, and the respiration was 50 per min. The pulse was $150 \mathrm{bpm}$ and the blood pressure was $65 / 35 \mathrm{mmHg}$. The blood oxygen saturation was $94 \%$. The nutrition and development was normal, and the mental response was satisfactory. Ochrodermia was observed in the whole body skin. Visual determination of bilirubin was $5-10 \mathrm{mg} / \mathrm{dl}$. There was no edema. The anterior fontanelle was soft and plain. No aberrant changes were noticed in the lung, heart, abdomen and the nervous system. For the blood routine examination, the hemoglobin was $51 \mathrm{~g} / \mathrm{L}$. The mean corpuscular volume (MCV) was $81.5 \mathrm{fL}$. The mean hemoglobin was $29.3 \mathrm{pg}$. The mean hemoglobin concentration was $384 \mathrm{~g} / \mathrm{L}$. The red cell distribution width was $53.8 \mathrm{fL}$. Ten intermediate erythroblasts and three acidophilic erythroblasts were identified per 100 leukocytes. The proportion of reticulocyte was $12.3 \%$. The number of leukocyte was $11.03 \times 10^{9} / \mathrm{L}$. The proportion of lymphocytes, neutrophils, monocytes, eosinophils, and basophil was $60 \%, 31 \%, 7 \%, 1 \%$ and $1 \%$, respectively. The platelet count was $333 \times 10^{9} / \mathrm{L}$. The concentration of C-reactive protein was less than $2.5 \mathrm{mg} / \mathrm{L}$. Blood smear findings indicated that the erythrocyte maturity was not the same (Figure 1), in which spherocytes accounted about $5 \%$ in total. Hemolysis findings revealed that the proportion of alkali-resistant hemoglobin was $47.97 \%$, while the acidified glycerin hemolysis test (AGLT) was $110 \mathrm{sec}$ (control, $290 \mathrm{sec}$ ). No aberrant changes were noticed in the hemoglobin electrophresis and glucose-6-phosphate dehydrogenase (G-6-PD) activity. The concentration of ferritin was $588.6 \mu \mathrm{g} / \mathrm{L}$. The folic acid, vitamin B12 and serum iron were in the normal ranges. The unsaturated iron and the total iron binding capacity were lower than the normal ranges. For the biochemical analysis, the direct bilirubin, indirect bilirubin, and lactate dehydrogenase (LDH) was in a concentration of $11.2 \mu \mathrm{mol} / \mathrm{L}, 139.8 \mu \mathrm{mol} / \mathrm{L}$, and $553 \mathrm{U} / \mathrm{L}$, respectively. The liver and renal function was normal, and the blood gas analysis and electrolyte findings were normal. Serological test for the hemolysis indicated that the patient showed a type $\mathrm{O}$ blood (RHD positivity). Her mother showed a blood type of A (RHD positivity). The direct antiglobulin test, free antibody test and antibody release test were all negative. No abnormalities were noticed in the TORCH. The determination of autoantibody was normal, together with the ECG, echocardiography and imaging findings on the chest and abdomen. Ultrasonography indicated no abnormalities in the liver, gallbladder, spleen, kidneys and brain.

\section{Capture sequencing for exons}

Venous blood ( $2 \mathrm{~mL}$ ) was obtained using an Eppendorf tube containing EDTA. QIAamp blood DNA mini kit (Qiagen, USA) was used to extract the genome DNA. The obtained DNA was fragmented using DNA enzyme, followed by purification using magnetic beads and subsequent PCR amplification. The panel probe (Illumina Inc, USA) was used for the capture and purification twice, followed by PCR amplification and purification. The generated library was analyzed on the NextSeq 500 analyzer (Illumina Inc, USA) for the sequencing of the exons of the 302 hematological system disease related genes (e.g. ANK1, SPTA1, 
EPB42, SLC4A1, and SPTB). The mean sequencing depth was 100x. The obtained data were subject to bioinformatic analysis to identify the pathogenic genes.

Sanger sequencing test

According to the high-throughput sequencing results, SPTB mutation was verified using Sanger sequencing based on the neonatal and parental DNA samples. The venous blood was extracted from each individual using the QIAamp blood DNA mini kit (Qiagen, USA). Specific primers were designed using the Primer Premier 5.0 software for the coding region of the exon of the target gene (forward, 5 'CCGCTCATGGAATCCCAC-3'; reverse, 5'-GGAGTAGTGCCTCCTCCCTG-3'). PCR amplification was performed using the $2 \times$ PCR Master Mix polymerase (Qiagen, USA) on a ABI 9700 PCR facility (Life Technology, USA). The PCR amplification conditions were as follows: $95^{\circ} \mathrm{C}$, for $10 \mathrm{~min} ; 35$ cycles of $95^{\circ} \mathrm{C}$ for $30 \mathrm{sec}$, $60^{\circ} \mathrm{C}$ for $30 \mathrm{sec}$ and $72^{\circ} \mathrm{C}$ for $1 \mathrm{~min}$; and final extension at $72^{\circ} \mathrm{C}$ for $7 \mathrm{~min}$. After DNA purification, Sanger sequencing was performed on the ABI3500 analyzer (Life Technology, USA), followed by sequencing comparison with the reference sequences.

Contrastive analysis of tertiary structure of protein

SWISS-MODEL software was used to predict and compare the spatial structure of the wild type protein and the protein encoded by mutation genes (https://www.swissmodel.expasy.org/). Meanwhile, the effects of SPTB gene mutation on coding protein were justified, in order to speculate the pathogenicity of the new protein.

Ethical approval

Written informed consent was obtained from the neonate's parents. The study protocols were approved by the Ethical Committee of Tianjin Children's Hospital.

\section{Results}

Genetic analysis findings

Based on the determination of the crucial splicing signals on the exons and introns of the 302 known pathogenic genes (e.g. ANK1, SPTA1, EPB42, SLC4A1 and SPTB) for the genetic deficiency of erythrocyte, a heterozygous pathogenic gene was identified in SPTB gene. A mutation c.3737delA on the exon 16 of SPTB (14q23|NM_000347.5), leading to mutation of p.(Lys1246fs) in amino acid sequence, was identified in the exon 16. Additionally, the same mutation was identified in her father. Such mutation was a type of frame-shifting mutation, resulting in frame-shifting since Lys1246. We speculated that it may lead to loss of normal function due to termination of the coded protein. Moreover, such mutation was not available in the HGMD database, ESP6500siv2_ALL, 1000g2015aug_ALL and dbSNP147 database. Taken together, c.3737delA on the exon 16 of SPTB identified in our study was a novel pathogenic mutation. The sequencing data of the SPTB gene in the patient and her father were shown in Figure 2. 
Prediction of protein structure

Figure 3A showed the prediction results of the tertiary structure of SPTB protein (817-1265) using the SWISS-MODEL software. The predicted template was 4uxv.1.A (PDB ID). Figure 3B summarized the prediction data of the protein sequence with a mutation on 1246 . Compared with the tertiary structure of wild type protein, the c.3737del A (p.lys1246 fs) mutation resulted in premature termination of the protein, triggering the loss of the subsequent alpha-spiral.

\section{Treatment and outcome}

Upon admission, the patient received phototherapy. Type 0 washed red blood cells were supplemented to correct the anemia, together with supporting therapy. The whole treatment duration was 4 days. The jaundice showed remission, and the anemia was corrected. Finally, the patient showed satisfactory outcome. In the 9-month follow-up, the patient received erythrocytes supplementation due to anemia about 3 and 7 months after discharge from the hospital. No jaundice, splenectasis or liver dysfunction was noticed.

\section{Discussion}

$\mathrm{HS}$, affecting the individuals worldwide, shows a prevalence of 27.6 per million Chinese population. In the neonates aged $<1$ year, the HS prevalence is about $0.37 / 1$ million with a ratio of $1: 1$ in male and female neonates [6]. However, a higher trend of misdiagnosis rate is reported among these patients, and some patients with moderate manifestations are not diagnosed in clinical settings. As a matter of in fact, the value may be higher than the expectation [7].

For the pathogenesis of HS, it may be related to the deficiency of various membrane protein of the erythrocytes such as ankyrin-1, band 3, beta-spectrin, alpha-spectrin and protein 4.2, which resulted in decline of the surface area of the erythrocyte membrane in HS patients [8]. Meanwhile, the damage of HS erythrocytes with poor deformation capacity in the spleen is the major cause for the hemolysis. According to the gene deficiency of erythrocyte membrane protein, HS was divided into five types (Table 1), among which type 3 and 5 were of autosomal recessive inheritance with a lower prevalence $[1,9]$. In this case, the patient was diagnosed with type $2 \mathrm{HS}$, which was divided into autosomal dominant inheritance.

The typical features of HS include anemia, jaundice, splenomegaly and ceticulocytosis. The severity of HS is divided into asymptomatic state, mild, moderate and severe conditions according to the degree of anemia [10]. The majority of the patients showed mild HS, and up to $20-30 \%$ presented a purely compensated hemolysis as there was a balance between reticulocyte production and red cell destruction. Rare neonates presented anemia, splenomegaly or jaundice that was noticed in children and adults. For the neonatal HS, some showed fetal hydrops or severe anemia in the perinatal stage, while some were in an asymptomatic state. About $50 \%$ of the neonatal HS were anemia free at post-natal 1 week, and rare cases showed splenomegaly. Jaundice was the most common manifestation for neonatal HS [1, 11, 12]. The neonatal jaundice usually occur within few post-natal days. For the neonates with spherocytosis 
required blood transfusion, special attention should be paid to the risk of kernicterus. The hemoglobin concentration was in the normal range, however, the cases may develop transient or even severe anemia within a few post-natal weeks due to inadequate compensation to the splenic filtration function caused by lacking of appropriate reticulocytes. Most of these conditions showed remission within 12 months postpartum [10]. In this study, the neonate with HS was mainly featured by delayed remission of jaundice and severe anemia without kernicterus. The patient was followed up for 9 months, and blood transfusion was required to correct the anemia.

The diagnosis of HS is highly relied on the clinical manifestations, family history and peripheral blood smear findings. For the blood smear, HS patients showed alternations of spherocyte proportion associated with the severity of anemia, as well as presence of mushroom-shaped erythrocytes, poikilocytosis and acanthocyte [13]. According to the HS diagnosis guidelines proposed by the British Committee for Standards in Haematology [4], additional tests were not recommended for the HS patients with typical clinical manifestations and laboratory findings. As the clinical manifestations in the neonatal HS patients are not typical, and some patients usually present spherocytes, the diagnosis of HS in these patients is still difficult [10]. To our best knowledge, a parental history of HS was reported in the majority (65\%) of the neonates with HS. Therefore, understanding on the parental history of anemia and/or the family history of anemia, jaundice, splenectomy or early-stage cholelithiasis in the neonates with jaundice is crucial for the diagnosis of HS in clinical settings [1]. For the neonates showing jaundice suspected with HS, the erythrocyte index was required after complete blood count, especially the mean corpuscular hemoglobin concentration (MCHC), mean corpuscular volume (MCV), as well as the identification of spherocytes and polychromatic erythrocyte in the peripheral blood smear [14]. In the neonates with typical HS, the MCHC was higher than the range of 365-370 g/L. Additionally, decline of MCV was also considered as a standard for the evaluation. Usually, the HS ratio was calculated based on the ratio between MCV and MCHC. Based on the Intermountain Healthcare database [15], a screening test with an index of $\geq 0.36$ presenting $>99 \%$ specificity, a $7 \%$ positive predictive value, $97 \%$ sensitivity, and a $>99 \%$ negative predictive value considered the best option. The elevation of high density erythrocytes proportion of $(\geq 4 \%)$ and a difference between the MCV and mean spherocyte volume of $>9.6 \mathrm{fL}$ could serve as a positive predictor for HS [10]. In addition, the eosin-5-maleimide binding test, osmotic fragility test, Osmotic gradient ektacytometry, AGLT and pink test all contributed to the diagnosis of HS in clinical settings $[7,16,17]$. For the suspicious patients, gene test was required to assist the diagnosis $[10,11]$. In this study, the patient' father showed anemia with a family history of cholelithiasis, which was clinically manifested as delayed remission of jaundice and severe anemia. Besides, the peripheral blood test findings revealed a MCHC of $>370 \mathrm{~g} / \mathrm{L}$. Nevertheless, the HS ratio was less than 0.36 , and the AGLT was positive. Finally, diagnosis of HS was confirmed based on these findings and the gene test results.

HS is a rare disease of genetic deficiency lacking of appropriate treatment options. Currently, its treatment is mainly focused on the controlling of the severity. Phototherapy, lowering the bilirubin in the neonatal HS, is considered the major treatment therapy in the early period of post-partum. Moreover, it should be given immediately to those with a high level of bilirubin or a higher medium than the risk zone ( $>75$ th percentile zone). Furthermore, according to the guidelines proposed by the American Academy of Pediatrics [1], 
further blood exchange transfusion was needed. In cases of anemia signs, blood transfusion was also required. As the erythropoiesis was not relatively satisfactory in a certain post-partum period (1 week to 1 month), single administration of erythropoietin could be used, or applied spontaneously with the blood transfusion. Folic acid supplementation should be considered for those with moderate and severe HS, in order to prevent the complications associated with folic acid deficiency. About 12 months after delivery, splenectomy was not recommended. Splenectomy is effective for treating moderate and severe HS, however, it may lead to trauma, decline of immunity, and pulmonary hypertension induced by arterial and venous thrombosis. Total splenectomy seemed to be superior to that of the partial splenectomy [6, 18-21]. Individual follow-up schemes should be established for the HS children, which is mainly relied on the severity of anemia and the monitoring of the growth and development. Meanwhile, special care should be taken to the iron overload in the children underwent persistent blood transfusion [1].

STPB gene, encoding the beta subunit of spectrin, is a member of spectrin gene family. It was localized on $14 q 23.3$ with a length of $100 \mathrm{~kb}$, consisting of 38 exons. Its encoded proteins were mainly distributed in the heart and bone marrows. Upon binding with the ankyrin, the spectrin played crucial roles in the formation and stability of erythrocyte membrane. STPB gene mutation was associated with the type II spherocytosis, hereditary elliptocytosis and hemolytic anemia of newborn [22, 23]. Homology modeling technique is a mature technique that is commonly utilized in the structural biology, which can sharply reduce the differences between the protein sequences and the definite protein sequence by test. SWISSMODEL software is the first homology modeling server of protein that is completely automatized to date [24]. In this study, it was utilized for the analysis of spatial structure of the protein sequence encoded by SPTB gene. Compared with the predicted tertiary structure of the wild type protein, the alpha-spiral was no longer available due to premature termination of protein transcription induced by c.3737del A (p.lys 1246 fs) mutation. Such spatial alternation of the protein may finally result in functional changes of $\beta$-spectrin in the erythrocyte membrane, which then triggers the onset of the disease. The patient's father carried the similar mutation of STPB gene, but such mutation was not identified in her mother. Her father showed a history of anemia and cholelithiasis, and STPB gene deficiency was of autosomal dominant inheritance. On this basis, an HS risk of up to $50 \%$ was speculated in the second child in this family. During the follow up, genetic communication and suggestions were given to the parents, together with informing the guidelines about the giving birth to a new baby, in order to reduce the prevalence of HS and improve the birth and population quality.

In this study, we merely reported the single gene mutation of STPB. We only used the SWISS-MODEL software to analyze the spatial structure of the protein encoded by SPTB gene, without validating it using laboratory data. In future, we will focus on it.

\section{Conclusion}

In summary, we reported the clinical manifestations, laboratory findings, and gene sequencing results of one neonatal HS case. Besides, we summarized the epidemiological features, clinical manifestations, diagnosis and treatment of HS. In cases of a neonate with severe hyperbilirubinemia, special attention 
should be paid to the family history, erythrocyte index and findings of the peripheral blood smear. For the icterohemolytic neonates, the bilirubin should be monitored strictly, together with appropriate treatment. Particularly, the hemoglobin must be monitored in post-partum period from 1 week to 1 month. Gene sequencing contributes to the diagnosis of such disease. The identified c.3737delA p.(Lys1246fs) mutation resulted in loss of alpha-spiral after prediction with tertiary structure of protein. It led to dysfunction of $\beta$-spectrin in the erythrocyte membrane, triggering corresponding changes in the clinical and laboratory test findings. Early diagnosis and treatment would bring down the severity and poor outcome among the HS patients.

\section{Abbreviations}

MCV: mean corpuscular volume; AGLT: acidified glycerin hemolysis test; LDH: lactate dehydrogenase; HS: hereditary spherocytosis

\section{Declarations}

\section{Ethics approval and consent to participate}

The study protocols were approved by the Ethical Committee of Tianjin Medical University General Hospital.

\section{Consent to publish}

Written informed consent for the publication has been obtained from the patient. Consent for publication was also obtained from the patient's family.

\section{Availability of data and materials}

The datasets used and/or analyzed during the current study are available from the corresponding author on reasonable request.

\section{Competing interests}

The authors declare that they have no competing interests.

\section{Funding}

Not applicable. 


\section{Authors' contributions}

LY, data collection and analysis, wrote the manuscript.

$\mathrm{SL}$, data collection

SJB, FYL: protein prediction

SC, data collection

$\mathrm{LN}$, data collection

LGL, review the manuscript, and approval of the submission.

All authors have read and approved the manuscript, and ensure that this is the case.

\section{Acknowledgements}

Not applicable.

\section{References}

1. Suzuki H, Kiryluk K, Novak J, Moldoveanu Z, Herr AB, Renfrow MB, Wyatt RJ, Scolari F, Mestecky J, Gharavi AG et al. The pathophysiology of IgA nephropathy. Journal of the American Society of Nephrology : JASN.2011; 22:1795-1803.

2. Da Costa L, Suner L, Galimand J, Bonnel A, Pascreau T, Couque N, Fenneteau O, Mohandas N. Diagnostic tool for red blood cell membrane disorders: Assessment of a new generation ektacytometer. Blood cells, molecules \& diseases.2016; 56:9-22.

3. Perrotta S, Gallagher PG, Mohandas N. Hereditary spherocytosis. Lancet (London, England).2008; 372:1411-1426.

4. Bolton-Maggs PH, Langer JC, lolascon A, Tittensor P, King MJ. Guidelines for the diagnosis and management of hereditary spherocytosis-2011 update. British journal of haematology.2012; 156:37-49.

5. Manciu S, Matei E, Trandafir B. Hereditary Spherocytosis - Diagnosis, Surgical Treatment and Outcomes. A Literature Review. Chirurgia (Bucharest, Romania : 1990).2017; 112:110-116.

6. Wang C, Cui Y, Li Y, Liu X, Han J. A systematic review of hereditary spherocytosis reported in Chinese biomedical journals from 1978 to 2013 and estimation of the prevalence of the disease using a disease model. Intractable \& rare diseases research.2015; 4:76-81. 
7. Andolfo I, Russo R, Gambale A, lolascon A. New insights on hereditary erythrocyte membrane defects. Haematologica.2016; 101:1284-1294.

8. Farias MG. Advances in laboratory diagnosis of hereditary spherocytosis. Clinical chemistry and laboratory medicine.2017; 55:944-948.

9. He BJ, Liao L, Deng ZF, Tao YF, Xu YC, Lin FQ. Molecular Genetic Mechanisms of Hereditary Spherocytosis: Current Perspectives. Acta haematologica.2018; 139:60-66.

10. Wang X LA, Lu Y, et al. Novel compound heterozygous mutations in the SPTA1 gene, causing hereditary spherocytosis in a neonate with Coombs negative hemolytic jaundice. Molecular Medicine Reports.2019; 19:2801-2807.

11. Christensen RD, Nussenzveig RH, Yaish HM, Henry E, Eggert LD, Agarwal AM. Causes of hemolysis in neonates with extreme hyperbilirubinemia. Journal of perinatology : official journal of the California Perinatal Association.2014; 34:616-619.

12. King MJ, Garcon L, Hoyer JD, Iolascon A, Picard V, Stewart G, Bianchi P, Lee SH, Zanella A. ICSH guidelines for the laboratory diagnosis of nonimmune hereditary red cell membrane disorders. International journal of laboratory hematology.2015; 37:304-325.

13. Da Costa L, Galimand J, Fenneteau O, Mohandas N. Hereditary spherocytosis, elliptocytosis, and other red cell membrane disorders. Blood reviews.2013; 27:167-178.

14. Christensen RD, Yaish HM, Lemons RS. Neonatal hemolytic jaundice: morphologic features of erythrocytes that will help you diagnose the underlying condition. Neonatology.2014; 105:243-249.

15. Yaish HM CR, Henry E, Baer VL, Bennett ST. A simple method of screening newborn infants for hereditary spherocytosis. J Applied Hematol.2013; 4:27-32.

16. Llaudet-Planas E, Vives-Corrons JL. Osmotic gradient ektacytometry: A valuable screening test for hereditary spherocytosis and other red blood cell membrane disorders. 2018; 40:94-102.

17. Park S H PCJ, Lee B R, et al. Comparison Study of the Eosin-5\"-Maleimide Binding Test, Flow Cytometric Osmotic Fragility Test, and Cryohemolysis Test in the Diagnosis of Hereditary Spherocytosis. American Journal of Clinical Pathology.2014; 142:474-484.

18. Baloira A, Bastos M, Pousada G, Valverde D. Pulmonary arterial hypertension associated with hereditary spherocytosis and splenectomy in a patient with a mutation in the BMPR2 gene. Clinical case reports.2016; 4:752-755.

19. Bader-Meunier B, Gauthier F, Archambaud F, Cynober T, Mielot F, Dommergues JP, Warszawski J, Mohandas N, Tchernia G. Long-term evaluation of the beneficial effect of subtotal splenectomy for management of hereditary spherocytosis. Blood.2001; 97:399-403. 
20. Abdullah F, Zhang Y, Camp M, Rossberg MI, Bathurst MA, Colombani PM, Casella JF, Nabaweesi R, Chang DC. Splenectomy in hereditary spherocytosis: Review of 1,657 patients and application of the pediatric quality indicators. Pediatric blood \& cancer.2009; 52:834-837.

21. Guizzetti L. Total versus partial splenectomy in pediatric hereditary spherocytosis: A systematic review and meta-analysis. Pediatric blood \& cancer.2016; 63:1713-1722.

22. Boguslawska DM, Heger E, Machnicka B, Skulski M, Kuliczkowski K, Sikorski AF. A new frameshift mutation of the beta-spectrin gene associated with hereditary spherocytosis. Annals of hematology.2017; 96:163-165.

23. Shin S, Jang W, Kim M, Kim Y, Park SY, Park J, Yang YJ. Targeted next-generation sequencing identifies a novel nonsense mutation in SPTB for hereditary spherocytosis: A case report of a Korean family. Medicine.2018; 97:e9677.

24. Waterhouse A, Bertoni M, Bienert S, Studer G, Tauriello G, Gumienny R, Heer FT, de Beer TAP, Rempfer C, Bordoli L et al. SWISS-MODEL: homology modelling of protein structures and complexes. Nucleic acids research.2018; 46:W296-w303.

\section{Table}

Table 1. Correlation between the gene and phenotype of the HS

\begin{tabular}{|c|c|c|c|c|c|c|}
\hline Type & Gene & $\begin{array}{l}\text { Gene } \\
\text { location }\end{array}$ & Protein & $\begin{array}{l}\text { Genetic } \\
\text { type }\end{array}$ & Percentage & Severity \\
\hline $\begin{array}{l}\text { Type 1, } \\
\text { OMIM:182900 }\end{array}$ & ANK1 (612641) & $8 p 11.21$ & Ankyrin-1 & $\begin{array}{l}\text { Autosomal } \\
\text { dominant }\end{array}$ & $40-50$ & $\begin{array}{l}\text { Mild and } \\
\text { moderate }\end{array}$ \\
\hline $\begin{array}{l}\text { Type } 2, \\
\text { OMIM: } \\
616649\end{array}$ & SPTB(182870) & $14 q 23.3$ & $\beta$-spectrin & $\begin{array}{l}\text { Autosomal } \\
\text { dominant }\end{array}$ & $15-30$ & $\begin{array}{l}\text { Mild and } \\
\text { moderate }\end{array}$ \\
\hline $\begin{array}{l}\text { Type 3, } \\
\text { OMIM: } \\
270970\end{array}$ & SPTA1(182860) & $1 q 23.1$ & $\alpha$-spectrin & $\begin{array}{l}\text { Autosomal } \\
\text { recessive }\end{array}$ & $<5$ & Severe \\
\hline $\begin{array}{l}\text { Type 4, } \\
\text { OMIM: } \\
612653\end{array}$ & SCL4A1 (109270) & $17 q 21.31$ & Band-3 & $\begin{array}{l}\text { Autosomal } \\
\text { dominant }\end{array}$ & $20-35$ & $\begin{array}{l}\text { Mild and } \\
\text { moderate }\end{array}$ \\
\hline $\begin{array}{l}\text { Type 5, } \\
\text { OMIM: } \\
612690\end{array}$ & EPB42(177070) & $15 q 15.2$ & Protein 4.2 & $\begin{array}{l}\text { Autosomal } \\
\text { recessive }\end{array}$ & $<5$ & $\begin{array}{l}\text { Mild and } \\
\text { moderate }\end{array}$ \\
\hline
\end{tabular}




\section{Figures}

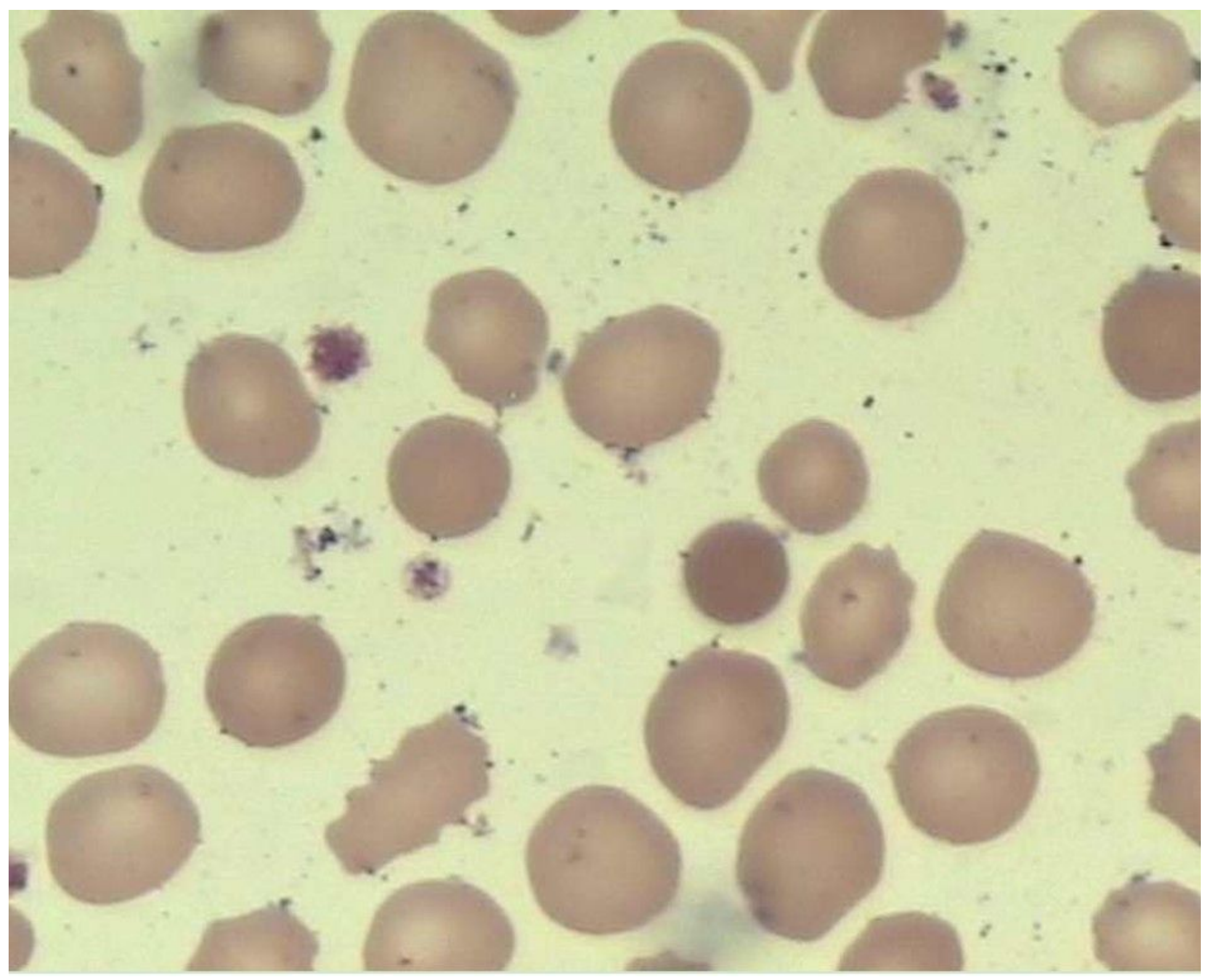

Figure 1

Morphology of erythrocytes in the blood smear. 
$\underline{A}$

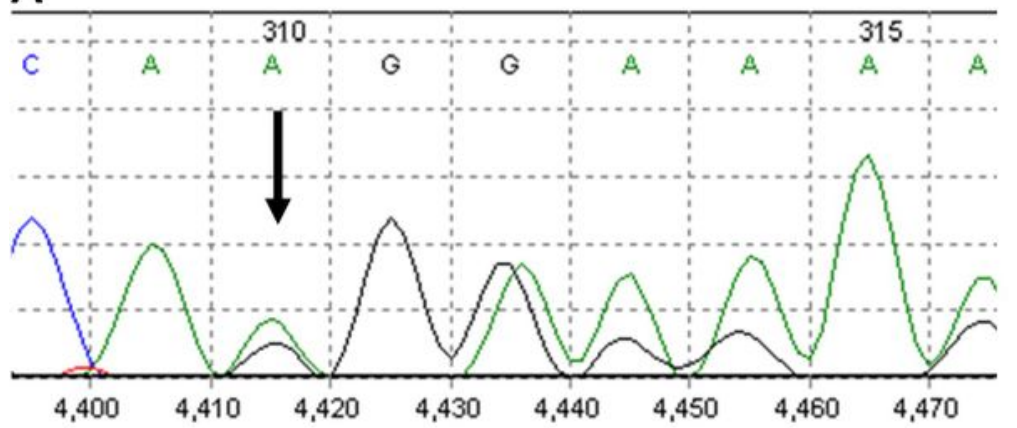

B

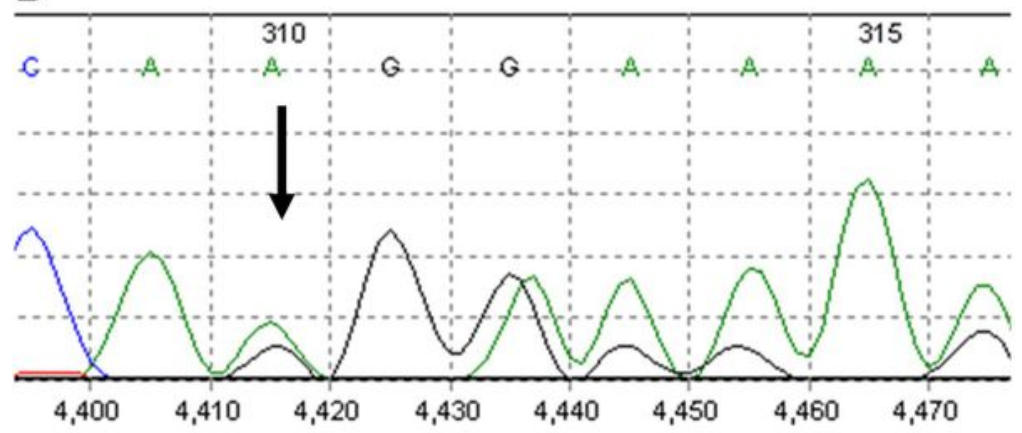

C

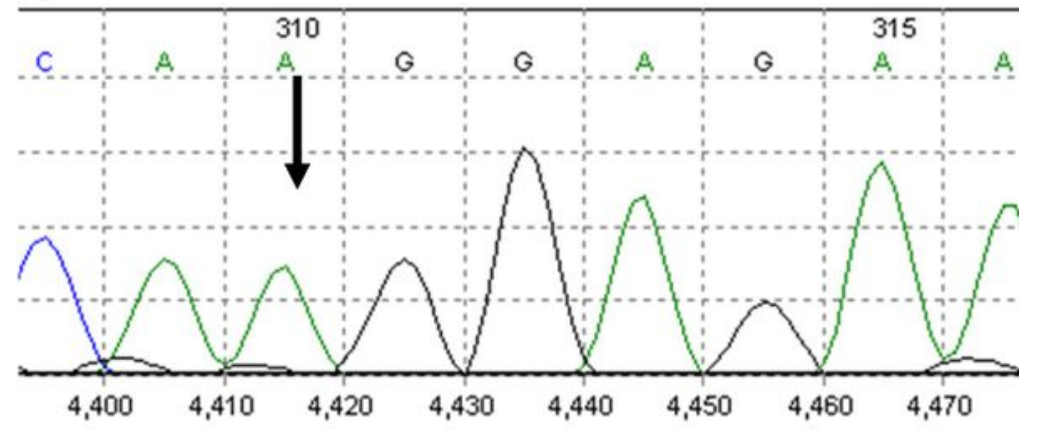

D

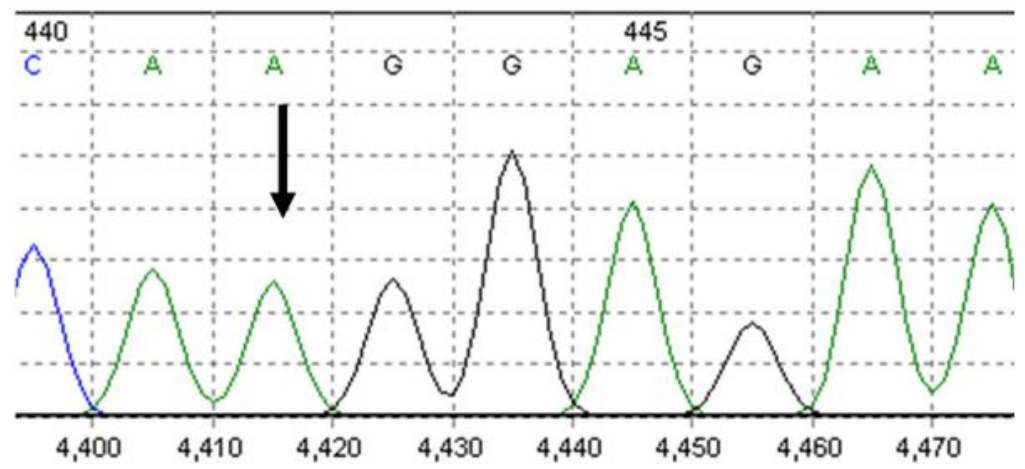

Figure 2

Gene sequencing results of the SPTB gene in the child (A), her father (B), her mother (C) and the referencing sequences (D). 

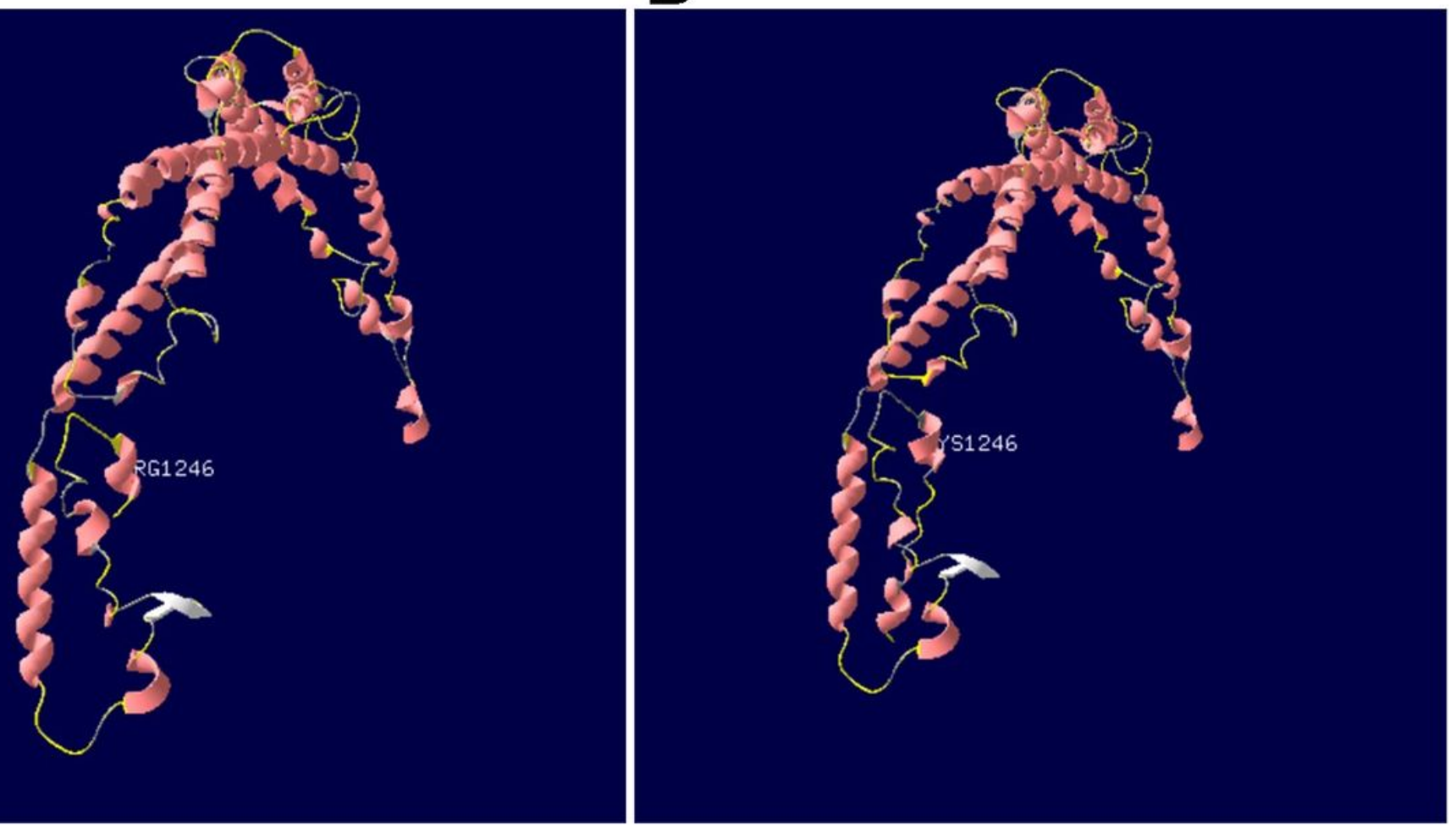

Figure 3

Protein prediction using the SWISS-MODEL software. A: normal protein tertiary structure. B: Tertiary structure of mutated protein.

\section{Supplementary Files}

This is a list of supplementary files associated with this preprint. Click to download.

- CAREchecklist.jpg 